\title{
BIRTH ORDER EFFECT ON ORAL HEALTH IN A GROUP OF EGYPTIAN CHILDREN
}

\author{
Manar Mohammed $^{*}$ and Yomna S.A.Mohamed
}

\begin{abstract}
Background: Dental caries is one of the major widespread health issues that continue to negatively affect the oral health of children globally.

Aim: Determination of the relationship between the sibling order and dental caries experience in children.

Subjects and Methods: A descriptive cross-sectional study was carried out from outpatient children aged 3-12 seeking treatment in the dental clinic of October 6 university hospital .An interviewer-administered questionnaire was used to obtain information from the parents on demographics and family structure including birth rank as well oral hygiene measure. The dental caries status of the children was assessed using WHO standard criteria for primary and mixed dentition.
\end{abstract}

Statistical analysis : Kruskal-Wallis test was used to compare between caries indices in children with different orders in the family. Also linear regression model was constructed using dependent and independent variables.

Results: There was not statistical significant difference between sibling orders and dental caries .Age was the only statistically significant predictor of DMF. Also Frequency of brushing was the only statistically significant predictor of $\mathrm{dmf}$.

Conclusion : No statistical significant difference between sibling orders and dental caries .

KEY WORDS: Children, birth order, dental caries, DMF, dmf.

\section{INTRODUCTION}

Despite the decrease in tooth decay in the pediatric population throughout the world; dental caries remains the most common childhood disease causing pain; chewing difficulties; general health disorders; psychological problems as well a substantial impact on quality of life ${ }^{(1)}$. Hence, dental caries is an international public health problem and early detection is important to establishing adequate preventive measures as well as avoiding premature treatment and consequent costs ${ }^{(2)}$.Habits acquired by children in early life continue to shape their attitude and lifestyle choices they make as adults..

* Lecturer, Department of Pediatric and community Dentistry, Faculty of Oral and Dental Medicine, October 6 University, Giza, Egypt. 
In harmony with the Social Learning theory these habits are largely acquired through observational learning and modeling ${ }^{(3)}$. It is believed that the family structure may play an important role in the development of dental caries in children because of the parental influence on oral hygiene practices and dietary habits of children ${ }^{(4)}$

Previous studies have shown that birth order usually affects children's health and may dictate the age of exposure to common childhood infections, under the assumption that firstborn children are not exposed until they enter school, while later-born children are exposed at an earlier age through their older siblings ${ }^{(5)}$. First born children are reported to have lower birth weight and more likely to have prenatal conditions, congenital malformations and to be hospitalized in early childhood compared to their later-born siblings ${ }^{(6)}$. However, the risk of older siblings is usually improved as they grow older since later-born children in large families are reported to be at an increased risk for injuries which is possibly related to less parental attention ${ }^{(7)}$.

Parents incorporate good habits in their children based on their own attitudes and beliefs. Various intergeneration processes connect between parental oral health status and that of their offspring. At the age of 5 years, a child's dietary choices and oral hygiene behavior, and consequently their dental health is predominantly dictated by their care givers. The choices parents make are influenced by a variety of factors which include their oral health attitudes, behaviors as well as various sociodemographic factors $^{(8)}$. Poor health is strongly associated with socioeconomic background and is transmitted across generations ${ }^{(9)}$.

The differences in general and oral health condition between siblings in a family could be due to many factors such as parental time and changes in the family environment due to the presence of children of different ages. The first-born child does not share parental time with any sibling at least during the first period in life. Since parental time is limited, succeeding children receive less quality time during their first years ${ }^{(10)}$.
Moreover, the psychosocial factors affecting the parents' ability to maintain the oral health of their children might be reflected in several variables that encompass the family structure. Accordingly, birth rank, family size, as well as at birth of the child and age-span characteristics of the family have been shown to be associated with the caries experience of preschool children $^{(11)}$.

Literature on the association between birth order and children's oral health status is scarce. In a few studies in that area, although risk of dental caries in later-born children compared to first-born children has been found to be higher ${ }^{(12)}$, conflicting results have also been reported ${ }^{(13)}$.

Thus, the objective was to study dental caries development in children in relation to their birth order in a group of Egyptian children.

\section{SUBJECTS AND METHODS}

\section{Study Design}

The present study is a cross-sectional study including 196 children; aged 3-12 from outpatients seeking treatment in the dental clinic of October 6 university hospital .Informed consent was taken from the parents prior to data collection. Data collection involved administration of a questionnaire to the parents and intraoral clinical examination of the children. A pretested and interviewer-administered questionnaire was used to obtain information on demographics and family structure. Family size (number of children in the family), birth ranks as well oral hygiene practice of the children participating in the study ${ }^{(13)}$.

Oral examination of the subjects was carried out after administering the questionnaire. It involved assessment of dental caries status of the child according to WHO criteria on a dental chair, in artificial light by using a plain mouth mirror and a dental probe. Caries severity was measured for permanent teeth by DMFT index, which records the number of $\mathrm{D}$ (decayed tooth), M (missing tooth) and F (filled tooth). For primary teeth the dmft index was used; $d$ (decayed teeth, m (missed teeth) and f (filled tooth). 
For mixed dentition deft index was used; $d$ (decayed tooth indicated for filling), e (decayed tooth indicated for extraction) and $\mathrm{f}$ (filled tooth) ${ }^{(14)}$.

\section{Sample size calculation}

This power analysis used deft index as the primary outcome. Based upon the results of Julihn A et al (2019) where the mean (SD) of deft were 0.12 (0.67) for first-born children and 0.68 (1.67) for fifth- or later born children, respectively. The calculated effect size (d) was 0.44 . Using alpha $(\alpha)$ level of $(5 \%)$ and Beta $(\beta)$ level of $(20 \%)$ i.e. power $=80 \%$; the minimum estimated sample size was 166 children. Sample size calculation was performed using $\mathrm{G}^{*}$ Power Version 3.1.9.2.

\section{Statistical Analysis}

Numerical data were presented as mean, standard deviation, median, range and 95\% Confidence Interval (95\% CI) for the mean values. Qualitative data were presented as frequencies and percentages. Caries indices scores showed non-parametric distribution, so Kruskal-Wallis test was used to compare between caries indices in children with different orders in the family. Linear regression model was used to determine significant predictors of caries using caries indices as the dependent variables while age, gender, frequency of brushing and order of the child in the family were the independent variables. The significance level was set at $\mathrm{P} \leq 0.05$. Statistical analysis was performed with IBM SPSS Statistics for Windows, Version 23.0. Armonk, NY: IBM Corp

\section{RESULTS}

\section{Demographic data:}

The present study was conducted on 196 children; 104 females $(53.1 \%)$ and 92 males $(46.9 \%)$. The mean (SD) values for age were 5.7 (2.2) years old with a minimum of 3 and a maximum of 12 years old. Seventy-three children (37.2\%) were first-born children in the family, 83 children $(42.3 \%)$ were second-born children, 30 children $(15.3 \%)$ were third-born children while 10 children $(5.1 \%)$ were forth-born children in the family.

\section{Frequency of tooth brushing:}

Ten children (5.1\%) don't brush their teeth, 52 children $(26.5 \%)$ brush it once daily, 72 children (36.7\%) brush it twice daily while 62 children (31.6\%) brush it three times daily.

\section{Caries indices:}

Descriptive statistics for DMF, dmf and def caries indices are presented in Table 1.

TABLE (1) Descriptive statistics for DMF, dmf and def caries indices in the study sample

\begin{tabular}{lcccc}
\hline $\begin{array}{l}\text { Caries } \\
\text { Index }\end{array}$ & $\mathrm{n}$ & Mean (SD) & $\begin{array}{c}\text { Median } \\
\text { (Range) }\end{array}$ & $\begin{array}{c}95 \% \text { CI for the } \\
\text { mean }\end{array}$ \\
\hline DMF & 63 & $0.68(1.19)$ & $0(0-6)$ & $0.38-0.98$ \\
dmf & 138 & $4.03(2.28)$ & $4(0-13)$ & $3.64-4.41$ \\
def & 55 & $4.15(3.09)$ & $4(0-13)$ & $3.31-4.98$ \\
\hline
\end{tabular}

\section{Comparison between caries indices in children with different orders (Table 2)}

TABLE (2) Descriptive statistics and results of Kruskal-Wallis test for comparison between caries indices in children with different order in the family

\begin{tabular}{|c|c|c|c|c|c|c|c|c|c|c|}
\hline \multirow{2}{*}{$\begin{array}{l}\text { Caries } \\
\text { index }\end{array}$} & \multicolumn{2}{|c|}{ First child } & \multicolumn{2}{|c|}{ Second child } & \multicolumn{2}{|c|}{ Third child } & \multicolumn{2}{|c|}{ Fourth child } & \multirow{2}{*}{ P-value } & \multirow{2}{*}{$\begin{array}{c}\text { Effect } \\
\text { size (Eta } \\
\text { Squared) }\end{array}$} \\
\hline & Mean (SD) & $\begin{array}{l}\text { Median } \\
\text { (Range) }\end{array}$ & Mean (SD) & $\begin{array}{l}\text { Median } \\
\text { (Range) }\end{array}$ & Mean (SD) & $\begin{array}{l}\text { Median } \\
\text { (Range) }\end{array}$ & Mean (SD) & $\begin{array}{l}\text { Median } \\
\text { (Range) }\end{array}$ & & \\
\hline DMF & $0.93(1.52)$ & $0(0-6)$ & $0.44(0.75)$ & $0(0-2)$ & $0.5(1.07)$ & $0(0-3)$ & \multicolumn{2}{|c|}{ Only one case } & 0.354 & 0.004 \\
\hline $\mathrm{dmf}$ & $4.25(2.76)$ & $4(0-13)$ & $4.12(1.93)$ & $4(0-12)$ & $3.21(2.11)$ & $3.5(0-8)$ & $4.44(1.81)$ & $5(2-7)$ & 0.288 & 0.006 \\
\hline def & $3.56(3.07)$ & $3(0-13)$ & $4.58(2.8)$ & $4.5(0-11)$ & $3.8(3.9)$ & $4(0-10)$ & \multicolumn{2}{|c|}{ Only one case } & 0.175 & 0.038 \\
\hline
\end{tabular}


There was no statistically significant difference between median DMF index in children with different child orders $(P$-value $=0.354$, Effect size $=0.004)$.

There was no statistically significant difference between median dmf index in children with different child orders $(P$-value $=0.288$, Effect size $=0.006)$.

There was no statistically significant difference between median def index in children with different child orders $(P$-value $=0.175$, Effect size $=0.038)$.

\section{Significant predictors of caries}

Linear regression model was constructed using DMF, dmf and def as the dependent variables while age, gender, frequency of brushing and order of child in the family were the independent variables. The results showed that age was the only statistically significant predictor of DMF $(\beta=0.201, P$-value $=0.014)$ indicating that older children have higher DMF index. Frequency of brushing was the only statistically significant predictor of $\operatorname{dmf}(\beta=-0.616$, $P$-value $=0.005)$ indicating that higher frequency of brushing is associated with lower dmf index scores. None of the independent variables was found to be a statistically significant predictor of def index. (Table 3,figure 1 and figure 2)

TABLE (3) Linear regression model results showing statistically significant predictors of DMF and dmf indices

\begin{tabular}{llccc}
\hline $\begin{array}{l}\text { Caries } \\
\text { index }\end{array}$ & $\begin{array}{l}\text { Independent } \\
\text { variable }\end{array}$ & $\begin{array}{c}\text { Regression } \\
\text { coefficient } \\
(\beta)\end{array}$ & $\begin{array}{c}95 \% \text { CI for } \\
(\beta)\end{array}$ & P-value \\
\hline \multirow{2}{*}{ DMF } & Age & 0.201 & $\begin{array}{c}0.042- \\
0.359\end{array}$ & $0.014^{*}$ \\
\hline \multirow{2}{*}{ dmf } & $\begin{array}{l}\text { Frequency } \\
\text { of brushing }\end{array}$ & -0.616 & $-1.041-$ & $0.005^{*}$ \\
& & & -0.192 & \\
\hline
\end{tabular}

*: Significant at $P \leq 0.05$

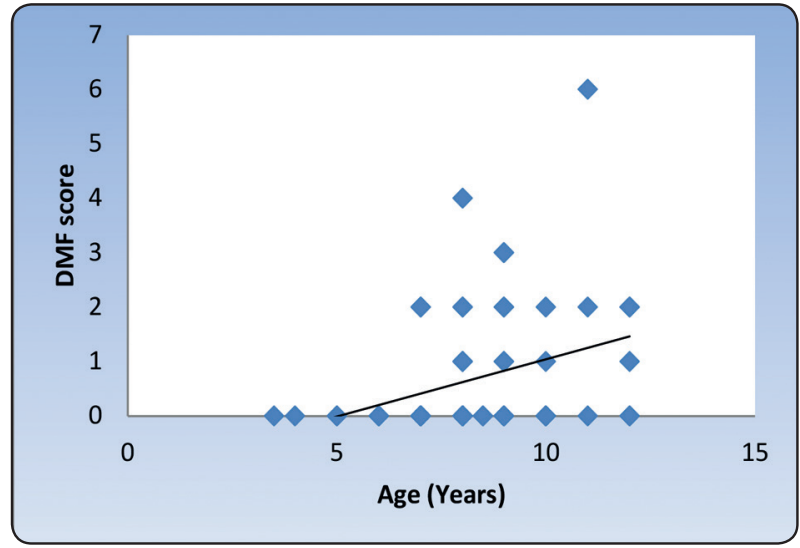

Fig. (1) Scatter diagram representing direct correlation between age and DMF index.

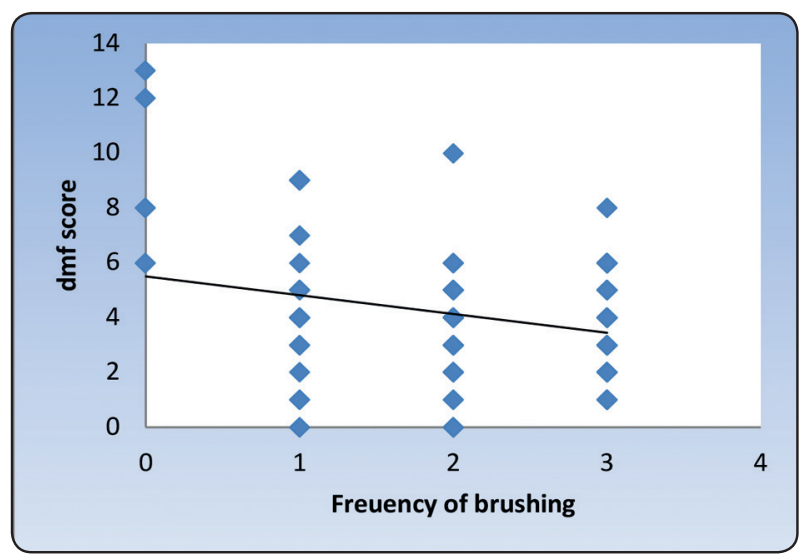

Fig. (2) Scatter diagram representing inverse correlation between frequency of brushing and $\mathrm{dmf}$ index.

\section{DISCUSSION}

Dental caries is one of the major widespread health issues that continues to adversely affect the oral health of children globally. The aim of this present study was to evaluate the relationship between the Sibling order and dental caries in children .This study was conducted on 196 children aged 3-12 years from outpatients seeking treatment in the dental clinic of October 6 university hospital.

Although Several studies have found that the first child in a family often show a better oral health compared to their siblings (Nicolau et al., $\mathbf{2 0 0 3}^{(15)}$; Mucci et al., 2004 ${ }^{(16)}$; Nicolau et al., 2005 $\left.{ }^{(17)}\right)$. Nicolau et al, in 2003 and 2005 found that those who were second or later in the family were statistically 
significantly more likely to have high DMFT scores. It may be because the first child is given full attention from their parents while still without siblings.Our results did not support the findings from previous studies on the association between birth order and dental caries. However, our findings agreed with the results of Wan Salina et al., 2007 ${ }^{(18)}$ who showed birth order has insignificant association with caries prevalence and there was not any association between birth order and dental caries. Further study with larger sample size, better design that examine each sibling in dental caries or a cohort study may provide more accurate information.

On comparing the Age with dental caries ,this study showed that with increasing of the age of the children, dental caries also increased which is in harmony with the findings of several studies that showed the child's increasing age can increase the risk of dental caries Shah et al., $2015^{(19)}$, Declerk et al., $2008{ }^{(20)}$ The possible reason could be the standard of living of the parents and children changes with the progress of years. However, the findings of this study disagreed with Goenka et al., $2018^{(21)}$ who observed that the prevalence of dental caries decreased as the age advanced.

Regarding brushing and dental caries prevalence, this study showed that frequency of brushing was statistically significant indicating that higher frequency of brushing is associated with lower $\mathrm{dmf}$ index scores, this finding in accordance with a study by Faraz et al., $2015{ }^{(22)}$ that showed dental caries incidence was low with daily brushing habit and statistically was significant for primary dentition.

Although, this study comprised $53.1 \%$ female and $46.9 \%$ males, however it was unable to show the relationship between gender and dental caries which is in accordance with some studies that showed that gender had no relationship with dental caries Shah et al., 2015 ${ }^{(19)}$, Chugh et al., 2018 ${ }^{(23)}$ However, in some other studies, boys were more inclined to develop dental caries as compared with the girl child Mahejabeen et al., $2006{ }^{(24)}$, and in some studies, girls children were more prone to develop dental caries as compared with the boys because girls have an early eruption of teeth as compared with the boys which results in prolonged contact with the oral environmental leading to dental caries Kurian et al $2016^{(25)}$.

\section{REFERENCES}

1. Clementino MA, Gomes MC, Pinto-Sarmento TCA, Martins CC, Granville-Garcia AF, Paiva SM. Perceived impact of dental pain on the quality of life of preschool children and their families. Plos One.2015; 10:e130602.

2. Cadavid AS, Lince CM, Jaramillo MC. Dental caries in the primary dentition of a Colombian population according to the ICDAS criteria. Braz Oral Res. 2010; 24:211-6.

3. Mattila ML, Rautava P, Sillanpaa M, Paunio P. Caries in five-year-old children and association with family-related factors. J Dent Res 2000;79:875-81.

4. Johnsen DC: The preschool 'passage': an overview of dental health. Dent Clin North Am 1995; 39: 695-707.

5. MacMahon B. Is acute lymphoblastic leukemia in children virus-related? Am J Epidemiol 1992;136:916-24.

6. Björkegren E, Svaleryd H. Birth order and child health. Institute for Evaluation and Labour Market and Education Policy (IFAU). Working paper 2017:16, ISSN 1651 -1166.

7. Bijur PE, Golding J, Kurzon M. Childhood accidents, family size and birth order. Soc Sci Med. 1988;26:839-43.

8. Bedos C, Brodeur JM, Arpin S, Nicolau B. Dental caries experience: A two-generation study. J Dent Res 2005;84:931-6.

9. Kumar S, Tadakamadla J, Kroon J, Johnson NW. Impact of parent-related factors on dental caries in the permanent dentition of 6-12-year-old children: A systematic review. J Dent. 2016;46:1-11.

10. Price J (2008) Parent-child quality time-does birth order matter? J Hum Resour;43:240-65.

11. Kiniros M, McCabe M: Familial and maternal factors affecting the dental health and dental attendance of preschool children. Community Dent Health 1995; 12: 226-229.

12. Wellappuli N, Amarasena N. Influence of family structure on dental caries experience of preschool children in Sri Lanka. Caries Res. 2012;46:208-12. 
13. Primosch RE. Effect of family structure on the dental caries experience of children. J Public Health Dent. 1982; 42:155-68.

14. World Health Organization: Oral Health Surveys: Basic Methods.World Health Organization, Geneva, Switzerland.1997.

15. Nicolau B, Marcenes W and Sheiham A. A life course approach to assessing causes of dental caries experience: the relationship between biological, behavioural, socioeconomic and psychological conditions and caries in adolescents. Caries Res 2003,37(5):319.

16. Mucci LA, Hsieh C-C, Williams PL, Dickman PW, Bjorlman L and Pedersen NL.B irth order, sibship size, and housing density in relation to tooth loss and periodontal disease: a cohort study among Swedish twins . Am j Epidemiol, 2004, 159:49.

17. Nicolau B, Marcenes W and Sheiham A Association between socioeconomic circumstances at two stages of life and adolescents oral health status, J Public Health Dent, 2005,65 (1):14-20.

18. Wan Salina WS, Nizam Ab, Naing L. The association of birth order and sociodemographic factors with caries experience among adolescents in Tumpat. Archives of Orofacial Sciences (2007) 2, 45-50 .

19. Shah AF Batra M, Aggarwal V, Dany SS, Rajput P, Bansal T. Prevalence of early childhood caries among preschool children of low socioeconomic status in district Srinagar, Jammu and Kashmir. Int Arch Integr Med [Internet] 2015; 2(3): 8-13.

20. Declerk D , Leroy R, Martens L, Lesaffre E, Garcia-Zattera MJ, Vanden-Broucke S, et al. Factors associated with prevalence and severity of caries experience in preschool children. Community Dent Oral Epidemiol 2008; 36:168-78.

21. Goenka, Dutta S, Marwah N, Sarawgi A, Nirwan M, and Mishra P Prevalence of Dental Caries in Children of Age 5 to 13 Years in District of Vaishali, Bihar, India Int J Clin Pediatr Dent. 2018 Sep-Oct; 11(5): 359-364.

22. Faraz A . Farooqi F, Khabeer A, Moheet I, Khan S, Farooq I, and ArRejaie A. Prevalence of dental caries in primary and permanent teeth and its relation with tooth brushing habits among schoolchildren in Eastern Saudi Arabi.Saudi Med J. 2015 Jun; 36(6): 737-742.

23. Chugh V K, Sahu K and and Chugh_A Prevalence and Risk Factors for Dental Caries among Preschool Children: A Cross-sectional Study in Eastern India.Int J Clin Pediatr Dent. 2018 May-Jun; 11(3): 238-243.

24. Mahejabeen R, Sudha P, Kulkarni SS, Anegundi R. Dental caries prevalence among preschool children of Hubli: Dharwad city. J Indian Soc Pedod Prev Dent. 2006 Mar;24(1):19-22.

25. Kurian J, Renganathan S, Gurusamy K, Shivashankarappa PG. Association between early childhood caries and age and gender specific height, weight and mid upper arm circumference of school children in Puducherry - "a comparative study” Biol Med Eng Sci Rep. 2016;2(1):13-17. 